\title{
Investigating the Phytochemicals and Antimicrobial Activities of Shoot and Root of Pycreus smithianus (Ridl.) C. B. Clarke (Family Cyperaceae)
}

\author{
P. A. Adeonipekun, T. A. Adeniyi, and S. O. Aminu \\ Department of Botany, Faculty of Science, University of Lagos, Akoka, Lagos 100121, Nigeria \\ Correspondence should be addressed to P. A. Adeonipekun; pladeonipekun@yahoo.com
}

Received 19 July 2014; Revised 18 December 2014; Accepted 18 December 2014; Published 31 December 2014

Academic Editor: M. Yasin Ashraf

Copyright ( 2014 P. A. Adeonipekun et al. This is an open access article distributed under the Creative Commons Attribution License, which permits unrestricted use, distribution, and reproduction in any medium, provided the original work is properly cited.

\begin{abstract}
Pycreus smithianus tubers have been reported to have insecticidal properties. To gain further insight into its medicinal values, phytochemical and antimicrobial studies were carried out on its shoot and root. The phytochemical screening indicated the presence of reducing sugars, tannins, flavonoids, terpenoids, cardiac glycosides, and saponins in varying quantities as well as absence of steroids and alkaloids. Aqueous and ethanolic extracts (shoot and root) were tested against two fungi-Aspergillus niger and Candida albicans - and two bacteria-Staphylococcus aureus and Salmonella typhi. Antimicrobial activity evaluation was carried out at 50 and $100 \mathrm{mg} / \mathrm{mL}$ concentrations by Agar Well Diffusion method. From the antimicrobial evaluation, the root ethanolic extract at $100 \%$ concentration was the most effective against S. aureus and C. albicans while the shoot ethanolic extract was effective against $S$. typhi. No extract was active against $A$. niger. Ethanolic extracts were more active than the aqueous extracts and showed higher inhibitory activity against the bacteria than the fungi. This is most likely due to the abundance of reducing sugars in the ethanolic extracts. From these findings, ethanolic extracts of the root of $P$. smithianus exhibited a good potential source of new drug for treating infections caused by these pathogens and particularly drug resistant C. albicans.
\end{abstract}

\section{Introduction}

It is no longer new that traditional medicine is increasingly becoming more popular than before. More than $80 \%$ of Nigerians use herbs for common ailments, not only because of the poor healthcare system in the country, but due to their relative availability and significance in primary health care cost [1] as well as the recent increasing media attention and campaign. Iwu et al. [2] remarked that the relative safety of herbal medicines also makes them more popular than synthetic drugs while Elujoba et al. [3] emphasized their significance in global primary healthcare. One of the most readily available plants, often neglected being a weed, is Pycreus smithianus of the family Cyperaceae.

Pycreus smithianus Ridley is a common weed of cultivated areas, moist places, and waste lands in Nigeria and West Africa [4]. Its inflorescence is a compact head type, $2 \mathrm{~cm}$ across, subtended by 3 or 4 conspicuous bracts. Its leaves are numerous, usually shorter than the flowering stems with $2-$ $4 \mathrm{~mm}$ width. The plant is much tufted with fibrous roots, $15-$ $45 \mathrm{~cm}$ tall, with the base of each stem often swollen. Apart from the tubers reported to possess aromatic substances used as insecticides and arachnicides [5], little or nothing is available on its medicinal values.

The aim of this work therefore is to evaluate the medicinal values of the shoot and root of P. smithianus through phytochemistry and antimicrobial studies.

\section{Materials and Methods}

2.1. Sample Source. P. smithianus plant was collected within the University of Lagos, Akoka Campus, Lagos, Nigeria. Taxonomic identification and confirmation were carried out at the University of Lagos Herbarium (LUH). The test fungi, Aspergillus niger and Candida albicans, and bacteria, 
Staphylococcus aureus and Salmonella typhi, were sourced from the Department of Pharmaceutical and Pharmacy Microbiology Laboratory, Faculty of Pharmacy, University of Lagos, Idi-Araba Campus, Lagos, Nigeria. Saboraud Dextrose Agar (SDA) was used to maintain the fungi while the bacteria strains were maintained on Mueller Hinton (MH) agar both at $4^{\circ} \mathrm{C}$.

2.2. Preparation of Plant Extracts. Plant materials were cut into pieces and oven-dried at $40^{\circ} \mathrm{C}$ (to avoid the loss of volatiles) for the period of one week. Dried samples were pulverized. To prepare the extracts, $100 \mathrm{~g}$ of pulverized plant materials (root and shoot) was weighed and soaked in $500 \mathrm{~mL}$ of ethanol and distilled water in four sterilized conical flasks and left for 48 hours. Whatman number 1 filter paper was used to filter the extracts and filtrates were concentrated under vacuum below $40^{\circ} \mathrm{C}$ using rotary evaporator to a volume of $10 \mathrm{~mL}$ [6].

2.3. Phytochemical Analysis. The phytochemical constituents of the plant samples (root and shoot) were screened qualitatively and quantitatively using the methods described by Harborne [7]. Screening involved tests for reducing sugars, alkaloids, cardiac glycosides, saponins, tannins, flavonoids, steroids, and terpenoids.

2.4. Antibacterial Assay. Agar Well Diffusion test method of Radhika and Aneja [8] was employed for both antibacterial and antifungal activity tests. Ten milliliters of Mueller Hinton $(\mathrm{MH})$ agar was poured into sterile petri dishes $(9 \mathrm{~cm})$ and allowed to set for the preparation of base plates. Molten $\mathrm{MH}$ agar held at $48^{\circ} \mathrm{C}$ was inoculated with a broth culture $\left(10^{3}\right.$ and $10^{4}$ bacteria per millilitre) of test organism and poured over the base plates forming homogenous top layer. A cup borer of $9 \mathrm{~mm}$ was used to bore holes. Two concentrations, $100 \%$ and $50 \%$, were prepared. To prepare $100 \%$ concentration, $5 \mathrm{~mL}$ of the extract was used while to prepare $50 \%$ concentration, $5 \mathrm{~mL}$ of the extract was diluted into two volumes (water for aqueous extract and ethanol for ethanolic extract). $0.2 \mathrm{~mL}$ of plant extracts was pippeted into the created well. This was repeated for plant parts' extracts and the controls. Two controls, ciprofloxacin and sterile distilled water, were used.Ciprofloxacin was also made into concentrations of $100 \%$ and $50 \%$ using half and full tablets. The plates were kept at room temperature for about 15 minutes and incubating was done at $37^{\circ} \mathrm{C}$ for 24 hours. Then the ratio of the inhibition zone $(\mathrm{mm})$ produced by the extracts and the inhibition zone around the ciprofloxacin reference $(\mathrm{mm})$ was used to express antibacterial activity.

2.5. Antifungal Assay. Ten milliliters of Saboraud Dextrose Agar (SDA) was poured into petri dishes and allowed to solidify. Liquid inoculum was prepared by pouring cool sterile distilled water on already grown fungal plates. The suspension was then transferred into a test tube. This was done in order to make the spores easily removable from the pure culture. Serial dilution from $10^{-1}, 10^{-2}, 10^{-3}$, and $10^{-4}$ was then carried out. A syringe was used to transfer $0.5 \mathrm{~mL}$ of the
TABLE 1: Qualitative analysis of extracts of Pycreus smithianus.

\begin{tabular}{lcccc}
\hline Test & \multicolumn{4}{c}{ Inference } \\
& $\begin{array}{c}\text { Root } \\
(\mathrm{aq})\end{array}$ & $\begin{array}{c}\text { Shoot } \\
(\mathrm{aq})\end{array}$ & $\begin{array}{c}\text { Root } \\
(\mathrm{eth})\end{array}$ & $\begin{array}{c}\text { Shoot } \\
(\mathrm{eth})\end{array}$ \\
\hline $\begin{array}{l}\text { Reducing sugars } \\
\text { Dragendorff's reagent }\end{array}$ & + & + & + & + \\
$\begin{array}{l}\text { (alkaloids) } \\
\text { Steroids }\end{array}$ & - & - & - & - \\
Tannins & - & - & - & - \\
Flavonoids & + & + & + & + \\
Terpenoids & + & + & - & + \\
Cardiac glycosides & + & + & - & + \\
Saponins & - & + & + & + \\
\hline
\end{tabular}

Key: eth: ethanolic extract; aq: aqueous extract; (-): absent; (+): present.

aliquots into each of the plates. A sterile rod was used to gently stir the spores for even distribution in the plates. The same cup boring process as done for the bacteria was followed. Two controls, clotrimazole and sterile distilled water, were used. Clotrimazole was also made into concentrations of $100 \%$ and $50 \%$ using half and full tablets. All the plates containing the extracts and fungi were incubated at $25^{\circ} \mathrm{C}$ after which the zones of inhibition were measured after 48 hours of incubation [8].

\section{Results}

3.1. Qualitative Phytochemical Analysis. From the qualitative phytochemical study of root and shoot of P. smithianus, reducing sugars and tannins were present while alkaloids and steroids were absent in both extracts and plant parts. The root and shoot aqueous extracts also showed the presence of flavonoids and terpenoids which were also present in the ethanolic extracts but were found only in the shoot. Cardiac glycosides and saponin were recorded for the ethanolic extracts of the root and shoot (Table 1).

3.2. Quantitative Phytochemical Analysis. The proportion of tannins was higher in the shoot than the root as indicated for both solvents. Aqueous extract of the root recorded the highest percentage for saponins while the aqueous extracts of both parts had relatively higher percentages of flavonoids and phenols than the ethanolic. Ethanolic shoot and root extracts contained high values of reducing sugars compared to the other phytochemicals (Table 2).

3.3. Antibacterial Activity Test. The antibacterial activity tests on the extracts of root and shoot of $P$. smithianus revealed that the $100 \%$ and $50 \%$ concentrations of the shoot and root ethanolic extracts were active against $S$. typhi while the aqueous extracts showed no activity (Table 3). Values of the shoot extract were higher than that of the root. This inhibitory activity of the ethanolic extracts increased at higher concentration. However, against S. aureus, the shoot aqueous and root ethanolic extracts showed inhibitory 
TABLE 2: Quantitative analysis of extracts of Pycreus smithianus.

\begin{tabular}{|c|c|c|c|c|c|}
\hline \multirow{2}{*}{ Extracts } & \multicolumn{5}{|c|}{ Phytochemicals/(\%/100 g) } \\
\hline & Tannin & Reducing sugar & Flavonoids & Phenol & Saponin \\
\hline Root (aq) & 0.01591 & 2.32065 & 0.16009 & 0.0356 & 0.79228 \\
\hline Shoot (aq) & 0.04855 & 0.85326 & 0.12432 & 0.01445 & $* *$ \\
\hline Root (eth) & 0.0184 & 4.09239 & $* *$ & 0.0133 & 0.74816 \\
\hline Shoot (eth) & 0.02887 & 4.14674 & 0.10286 & 0.00834 & 0.69363 \\
\hline
\end{tabular}

Key: eth: ethanolic extract; aq: aqueous extract; $* *$ : not present.

TABLE 3: Measurement of antibacterial inhibition zones.

\begin{tabular}{|c|c|c|c|}
\hline \multirow{2}{*}{ Bacteria } & \multirow{2}{*}{ Extracts } & \multicolumn{2}{|c|}{ Zone of inhibition (mm) } \\
\hline & & $100 \%$ & $50 \%$ \\
\hline \multirow{6}{*}{ Salmonella typhi } & Root (aq) & na & na \\
\hline & Shoot (aq) & na & na \\
\hline & Root (eth) & $15.25^{\mathrm{a}} \pm 0.51^{\mathrm{b}}$ & $11.75^{\mathrm{a}} \pm 0.25^{\mathrm{b}}$ \\
\hline & Shoot (eth) & $21.25^{\mathrm{a}} \pm 0.51^{\mathrm{b}}$ & $20.38^{\mathrm{a}} \pm 0.38^{\mathrm{b}}$ \\
\hline & Ciprofloxacin & $28.88^{\mathrm{a}} \pm 0.13^{\mathrm{b}}$ & $26.88^{\mathrm{a}} \pm 0.13^{\mathrm{b}}$ \\
\hline & Water & na & na \\
\hline \multirow{6}{*}{ Staphylococcus aureus } & Root (aq) & na & na \\
\hline & Shoot (aq) & $17.13^{\mathrm{a}} \pm 0.13^{\mathrm{b}}$ & $14.38^{\mathrm{a}} \pm 0.13^{\mathrm{b}}$ \\
\hline & Root (eth) & $30.25^{\mathrm{a}} \pm 0.76^{\mathrm{b}}$ & $26.88 \pm 0.13^{\mathrm{b}}$ \\
\hline & Shoot (eth) & na & na \\
\hline & Ciprofloxacin & $32.88^{\mathrm{a}} \pm 0.13^{\mathrm{b}}$ & $28.63^{\mathrm{a}} \pm 0.38^{\mathrm{b}}$ \\
\hline & Water & na & na \\
\hline
\end{tabular}

Key: ${ }^{a}$ mean of triplicates (including diameter of borer), ${ }^{\text {b }}$ standard error, aq: aqueous extract, na: no inhibition, and eth: ethanolic extract.

activities at both concentrations while other extracts showed no activity.

3.4. Antifungal Activity Test. The antifungal activity tests, carried out on aqueous and ethanolic extracts of root and shoot of studied sedge, showed that no extract was active against $A$. niger at all concentrations. However, the root ethanolic extract showed strong activity compared to the control against C. albicans at both concentrations (Table 4). The inhibitory activity of the root ethanolic extract increased at higher concentration.

\section{Discussion}

Six types of phytochemicals were revealed present in the shoot ethanolic extract. They are reducing sugars, terpenoids, tannins, flavonoids, saponins, and cardiac glycosides. The shoot ethanolic extract was followed by the root and shoot aqueous extracts with five phytochemicals each. Phytochemicals of the root ethanolic extract were the least in number, four, but they were, nonetheless, the most active (Table 1). The phytochemical screening showed that higher proportions of reducing sugars are present in the ethanolic extracts with only the root aqueous indicating appreciable presence while sugars are in low proportion in the shoot aqueous (Table 2). Kodera et al. [9] and Dhalel and Markandeya [10] have remarked that the combination of the reducing sugars constitutes a building block in the production of phytoalexins which are antimicrobial substances synthesized by plants. Phytoalexins accumulate rapidly at areas of incompatible pathogen infection. The abundance of reducing sugars in the root ethanolic extract could account for its high antibacterial activity (Table 3 ). This agrees with previous works of Dhalel and Markandeya [10] and Mills-Robertson et al. [11] on the antibacterial property of reducing sugars. Phenols and tannins are other significant phytochemicals present in all the four extracts. Phenols have been reported to have antiseptic, anti-inflammatory, antimicrobial, and antitumor properties [12]. Tannins have also been reported by Okigbo et al. [12] to have soothing, skin regeneration, and anti-inflammatory as well as diuretic properties. Flavonoids and saponins, though present in appreciable proportions, are absent in root ethanolic and shoot aqueous, respectively (Table 2). Flavonoids have been reported to have antimicrobial activities [13]. However, the abundance of flavonoids in the root aqueous extract could not give the extract the expected antimicrobial activity while the root ethanolic extract that lacked flavonoids has very good antimicrobial activity (Tables 3 and 4). Cushnie and Lamb [13] remarked that reported antimicrobial activity of flavonoids is controversial, perhaps due to "the interand intraassay variation in susceptibility testing." From the present work, it was revealed that steroids and alkaloids are both absent in P. smithianus (Table 1). Okigbo et al. [12] described alkaloids as being useful in medicine for their analgesic, antispasmodic, and bactericidal effects. However, the presence of reducing sugars, phenols, and tannins in 
TABLE 4: Measurement of antifungal inhibition zones.

\begin{tabular}{|c|c|c|c|}
\hline \multirow{2}{*}{ Fungi } & \multirow{2}{*}{ Extracts } & \multicolumn{2}{|c|}{ Zone of inhibition (mm) } \\
\hline & & $100 \%$ & $50 \%$ \\
\hline \multirow{6}{*}{ Aspergillus niger } & Root (aq) & na & na \\
\hline & Shoot (aq) & na & na \\
\hline & Root (eth) & na & na \\
\hline & Shoot (eth) & na & na \\
\hline & Clotrimazole & $28.88^{\mathrm{a}} \pm 0.13^{\mathrm{b}}$ & $26.88^{\mathrm{a}} \pm 0.13^{\mathrm{b}}$ \\
\hline & Water & na & na \\
\hline \multirow{6}{*}{ Candida albicans } & Root (aq) & na & na \\
\hline & Shoot (aq) & na & na \\
\hline & Root (eth) & $13.62^{\mathrm{a}} \pm 0.38^{\mathrm{b}}$ & $11.25^{\mathrm{a}} \pm 0.25^{\mathrm{b}}$ \\
\hline & Shoot (eth) & na & na \\
\hline & Clotrimazole & $17.50^{\mathrm{a}} \pm 0.25^{\mathrm{b}}$ & $15.88^{\mathrm{a}} \pm 0.13^{\mathrm{b}}$ \\
\hline & Water & na & na \\
\hline
\end{tabular}

Key: ${ }^{a}$ mean of triplicates (including diameter of borer), ${ }^{b}$ standard error, aq: aqueous extract, na: no inhibition, and eth: ethanolic extract.

all the extracts provides alternative sources of antimicrobial compounds in the plant. The presence and proportions of these other phytochemicals are significant enough to make $P$. smithianus a good source of these antimicrobial compounds.

From the assays, the shoot ethanolic extract seemed to lack bioactive forms against all other pathogens except S. typhi with the significant value of $100 \%: 21.25^{\mathrm{a}} \pm 0.51$, 50\%: $20.38^{\mathrm{a}} \pm 0.38$ as against the standard antibiotic control, ciprofloxacin $100 \%: 28.88^{\mathrm{a}} \pm 0.13,50 \%: 26.88^{\mathrm{a}} \pm 0.13$ (Tables 3 and 4 ). The root aqueous extract had the highest concentration of phenols and flavonoids among the tested four extracts. In spite of these high concentrations, this extract was inactive against all the tested microbes. The significance of the extraction solvent is underscored here since the root ethanolic extract on the other hand with no flavonoids showed good activity against three of the pathogens, C. albicans, $S$. typhi, and S. aureus (Tables 3 and 4 ). Therefore the extraction solvent determines to a great extent the activity of bioactive compounds in plant materials [14]. Root ethanolic extract had the least of four phytochemical types and, surprisingly, it has the only significant activity on C. albicans (Tables 1 and 4). Of significant note also are the root ethanolic and shoot aqueous extracts of $P$. smithianus against S. aureus (100\%: $17.13 \pm 0.13$; $50 \%: 14.38 \pm 0.13$ and $100 \%: 30.25 \pm 0.76 ; 50 \%$ : $26.88 \pm 0.13$, resp.). The root ethanolic extract inhibitory activity compares favourably with the control, ciprofloxacin $(150 \mu \mathrm{g} / \mathrm{mL}: 32.88 \pm 0.13 ; 75 \mu \mathrm{g} / \mathrm{mL}: 28.63 \pm 0.38)$ (Table 3$)$. This high inhibition by the root ethanolic extract against the tested bacteria indicates that the plant part can be used in medicine upon purification and isolation of its active compounds. The inactivity recorded for the root aqueous and shoot ethanolic extracts also demonstrates the importance of using the appropriate part of a plant in phytomedical work. This information is important in guiding users of this plant in herbal medicine and pharmacognosy to recognize the part to target for maximum and effective recovery of bioactive compounds.

The shoot ethanolic extract showed the greatest inhibition against S. typhi $(50 \% ; 20.38 \pm 0.38,100 \% ; 21.25 \pm 0.51)$ and significantly compares with the control ciprofloxacin (50\%; $26.88 \pm 0.13,100 \% ; 28.88 \pm 0.13$ ). Isolation and purification of the bioactive compounds responsible for this inhibitory activity may lead to the production of antibiotics which can be used effectively against $S$. typhi. A mild inhibitory action against S. typhi (100\%: $19.13 \pm 0.38)$ and (50\%: $17.25 \pm$ 0.25 ) was also shown by the root ethanolic extract. This further shows the antimicrobial potency of the ethanolic extract of this plant. The inactivity of the aqueous extracts against $S$. typhi demonstrates the inability of the extraction solvent to extract the active phytochemicals compared to the ethanolic extract (Table 3). There was no record of inhibition against $A$. niger by any of the extracts from the studied plant parts (Table 4). The observed inactivity of $A$. niger may be due to the mycotoxin called ochratoxin produced by some fungi among which are Aspergillus. Samson et al. [15] reported that this mycotoxin was produced by these fungi for resistance against antifungal drugs. Although Candida albicans is known to be resistant to most antimicrobial agents which was also shown in this work, the root ethanolic extract however showed some level of inhibition (100\%: $13.62 \pm$ 0.25 and 50\%: $11.25 \pm 0.25$ ) against the "stubborn" fungus (Table 4).

The ethanolic extracts showed higher antimicrobial activities than the aqueous extracts. This implies that ethanol extracted more active phytoconstituents compared to water and this agrees with the works of Eloff [16], Nwachukwu and Uzoeto, [17], Peni et al. [18], and Adeniyi et al. [19].

\section{Conclusion}

The study revealed that the root and shoot of $P$. smithianus have significant antimicrobial activity. The study further confirms that the ethanolic extracts of plants are more active than the aqueous extracts. The root ethanolic extract was the most active and could be an important source of natural antimicrobials particularly against "stubborn" C. albicans and thus recommended for isolation of the therapeutic antimicrobials and further pharmacological evaluation. Also, 
the root of the plant is richer in bioactive compounds than the shoot with respect to the antimicrobial activities. Extracts from $P$. smithianus show higher antibacterial than antifungal activity.

\section{Conflict of Interests}

The authors declare that there is no conflict of interests regarding the publication of this paper.

\section{Acknowledgments}

The authors appreciate the efforts of the Department of Pharmaceutical and Pharmacy Microbiology and Department of Botany, University of Lagos, as well as the University of Lagos Herbarium for the provision of microorganisms, the laboratory benchwork, and the identification of plant material, respectively.

\section{References}

[1] F. Awosika, "Traditional medicine as the solution to Nigerian health problems," Clinical Pharmacology and Herbal Medicine, vol. 9, pp. 26-31, 1993.

[2] M. M. Iwu, R. A. Duncan, and C. O. Okunji, "New antimicrobials of plant origin," in Perspectives on New Crops and New Uses, J. Janick, Ed., ASHS Press, Alexandria, Va, USA, 1999.

[3] A. A. Elujoba, O. M. Odeleye, and C. M. Ogunyemi, "Traditional Medical Development for medical and dental primary health care delivery system in Africa," African Journal of Traditional, Complementary and Alternative Medicines, vol. 2, no. 1, pp. 46-61, 2004.

[4] J. Lowe and D. Stanfield, The Flora of Nigeria; Sedges (Family Cyperaceae), University of Ibadan Press, Ibadan, Nigeria, 1974.

[5] H. Burkil, The Useful Plants of West Tropical Africa, Royal Botanical Garden, Kew, UK, 1985.

[6] A. Bag, S. Bhaltacharya, P. Bharati, N. Pal, and R. Chaltopadhyay, "Evaluation of antibacterial properties of Chebuliocmyrobalan (fruit of Terminalia chebula Retz.) extracts against methicillin resistant Staphylococcus aureus and trimethoprimsuphamethoxazole resistant unpathogenic Escherichia coli," African Journal of Plant Sciences, vol. 3, no. 2, pp. 25-29, 2009.

[7] J. Harborne, Phytochemical Methods: A Grade to Modern Techniques of Plant Analysis, Chapman and Hall, London, UK, 1998.

[8] J. Radhika and K. Aneja, "Antimicrobial activity of Amomum subulatum and Elettaria cardamomum against dental cariescausing microorganisms," Ethnobotanical Leaflets, vol. 13, pp. 840-849, 2009.

[9] Y. Kodera, M. Ichikawa, J. Yoshida et al., "Pharmacokinetic study of allixin, a phytoalexin produced by garlic," Chemical and Pharmaceutical Bulletin, vol. 50, no. 3, pp. 354-363, 2002.

[10] D. A. Dhalel and S. K. Markandeya, "Antimicrobial and phytochemical screening of Plumbago zeylanica linn. (Plumbaginaceae) leaf," Journal of Experimental Science, vol. 2, no. 3, pp. 4-6, 2011.

[11] F. C. Mills-Robertson, S. C. K. Tay, G. Duker-Eshun, W. Walana, and K. Badu, "In vitro antimicrobial activity of ethanolic fractions of Cryptolepis sanguinolenta," Annals of Clinical Microbiology and Antimicrobials, vol. 11, article 16, 2012.
[12] R. N. Okigbo, C. L. Anuagasi, and J. E. Amadi, "Advances in selected medicinal and aromatic plants indigenous to Africa," Journal of Medicinal Plants Research, vol. 3, no. 2, pp. 86-95, 2009.

[13] T. P. T. Cushnie and A. J. Lamb, "Antimicrobial activity of flavonoids," International Journal of Antimicrobial Agents, vol. 26, no. 5, pp. 343-356, 2005.

[14] H. J. de Boer, A. Kool, A. Broberg, W. R. Mziray, I. Hedberg, and J. J. Levenfors, "Antifungal and anti-bacterial activity of some herbal remedies from Tanzania," Journal of Ethnopharmacology, vol. 96, no. 3, pp. 461-469, 2005.

[15] R. A. Samson, J. A. M. P. Houbraken, A. F. A. Kuijpers, J. M. Frank, and J. C. Frisvad, "New ochratoxin A or sclerotium producing species in Aspergillus section Nigri," Studies in Mycology, vol. 50, no. 1, pp. 45-56, 2004.

[16] J. N. Eloff, "Which extractant should be used for the screening and isolation of antimicrobial components from plants?" Journal of Ethnopharmacology, vol. 60, no. 1, pp. 1-8, 1998.

[17] E. Nwachukwu and H. O. Uzoeto, "Antimicrobial activities of leaf of Vitexdoniana and Cajanus cajan on some bacteria," Researcher, vol. 2, no. 3, pp. 37-47, 2010.

[18] I. J. Peni, C. M. Elinge, H. Yusuf et al., "Phytochemical screening and antibacterial activity of Parinari curatellifolia stem extract," Journal of Medicinal Plants Research, vol. 4, no. 20, pp. 20992102, 2010.

[19] T. A. Adeniyi, P. A. Adeonipekun, and E. A. Omotayo, "Investigating the phytochemicals and antimicrobial properties of three sedge (Cyperaceae) species," Notulae Scientia Biologicae, vol. 6, no. 3, pp. 276-281, 2014. 

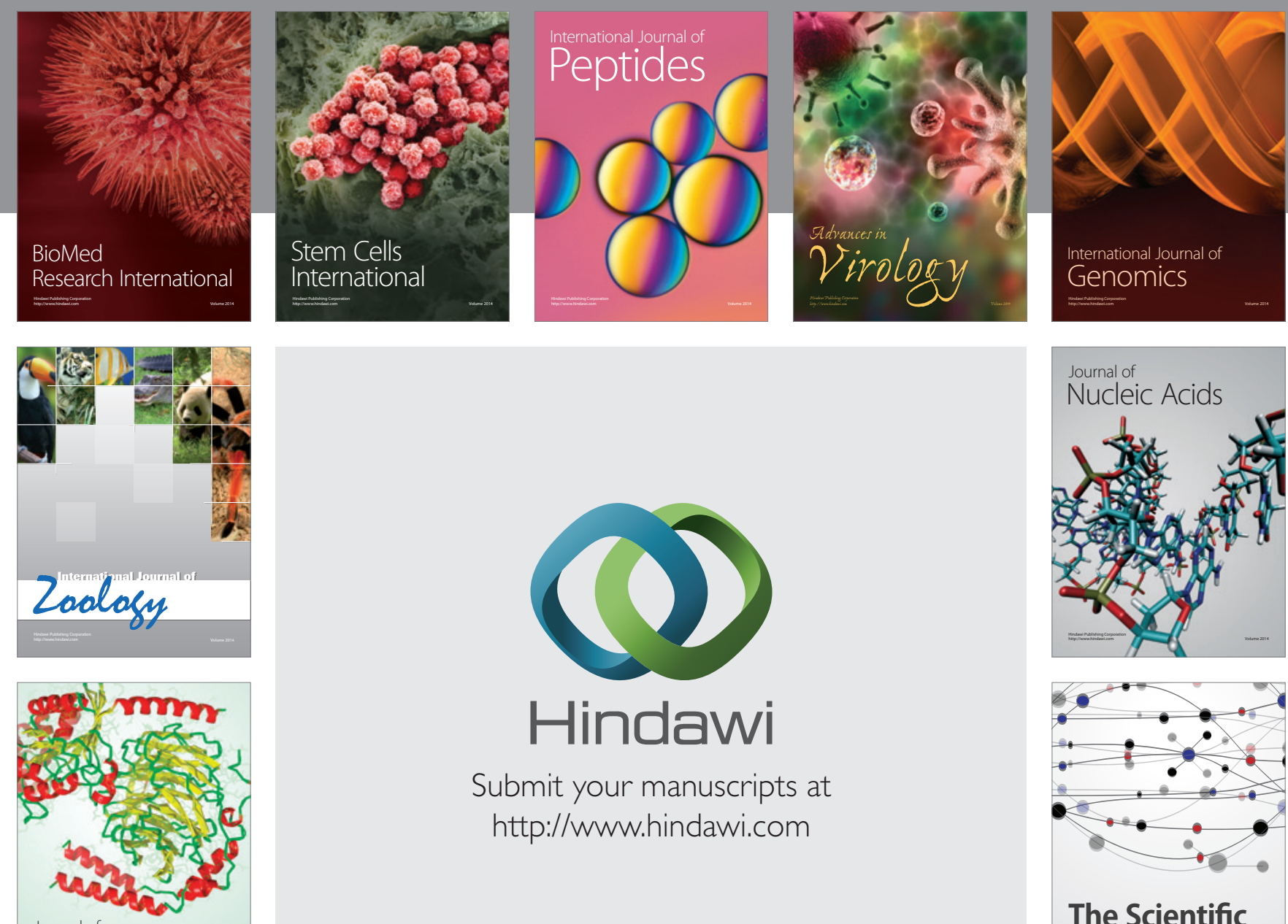

Submit your manuscripts at

http://www.hindawi.com

Journal of
Signal Transduction
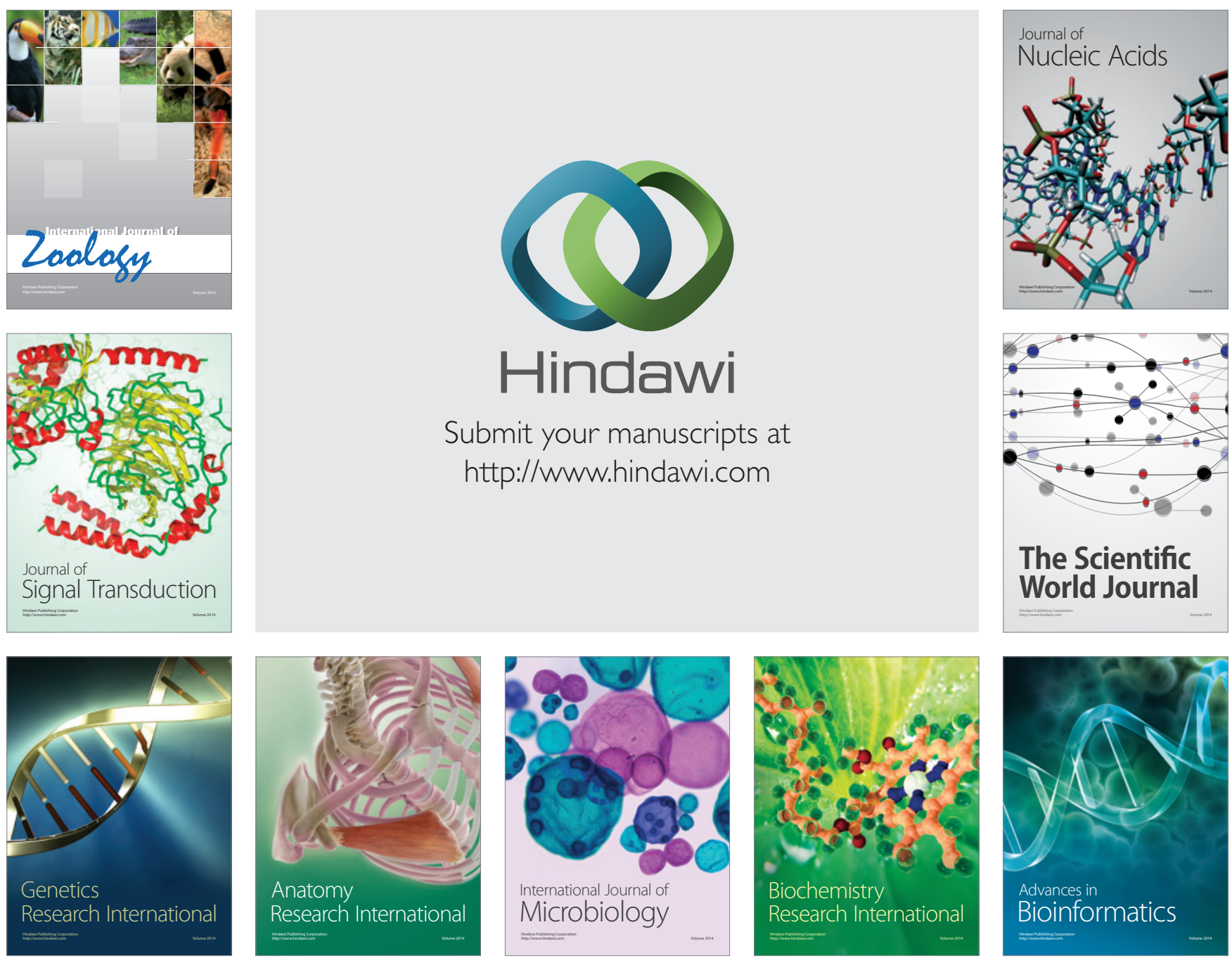

The Scientific World Journal
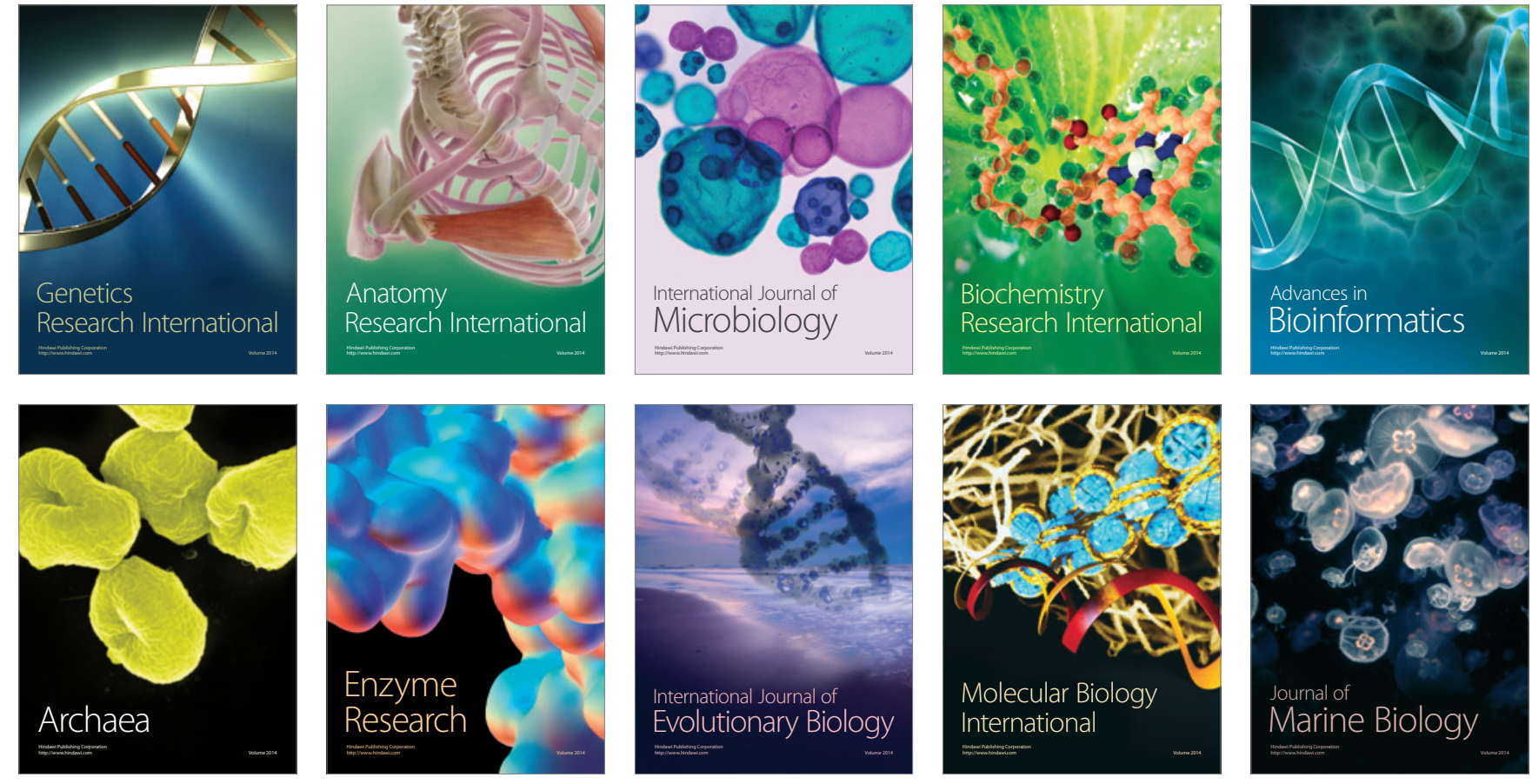